Check for updates

Cite this: Chem. Sci., 2018, 9, 8561

๑ All publication charges for this article have been paid for by the Royal Society of Chemistry

Received 19th April 2018

Accepted 13th September 2018

DOI: $10.1039 / \mathrm{c} 8 \mathrm{sc} 01777 \mathrm{~h}$

rsc.li/chemical-science

\section{Zwitterlation mitigates protein bioactivity loss in vitro over PEGylation $\uparrow$}

\author{
Yanjiao Han, (D) ${ }^{a}$ Zhefan Yuan, $^{\mathrm{b}}$ Peng Zhang (D) ${ }^{\mathrm{b}}$ and Shaoyi Jiang*ab
}

Conjugation with poly(ethylene glycol) (PEG) or PEGylation is a widely used tool to overcome the shortcomings of native proteins, such as poor stability, inadequate pharmacokinetic (PK) profiles, and immunogenicity. However, PEGylation is often accompanied by an unwanted detrimental effect on bioactivity, particularly, resulting from the amphiphilic nature of PEG. This is especially true for PEGylated proteins with large binding targets. Pegasys, a PEGylated interferon alpha-2a (IFN- $\alpha 2 a$ ) bearing a $40 \mathrm{kDa}$ branched PEG, is a typical example that displays only $7 \%$ in vitro activity of the unmodified IFN- $\alpha 2 a$. In this work, by employing IFN- $\alpha 2$ a as a model protein, we demonstrated that a protein conjugated with zwitterionic polymers (or zwitterlation) could significantly mitigate the antiproliferative bioactivity loss in vitro after polymer conjugation. The retained antiproliferative activity of zwitterlated IFN- $\alpha 2 \mathrm{a}$ is 4.4 -fold higher than that of the PEGylated IFN- $\alpha 2$ a with the same polymer molecular weight, or 3-fold higher than that of the PEGylated IFN- $\alpha 2 a$ with a similar hydrodynamic size. It is hypothesized that nonspecific interactions between zwitterionic polymers and IFN- $\alpha 2$ a/IFN- $\alpha 2$ a receptors can be mitigated due to the super-hydrophilic nature of zwitterionic polymers. This, in turn, reduces the 'nonspecific blocking' between IFN- $\alpha 2$ a and IFN- $\alpha 2$ a receptors. In addition, we demonstrated that zwitterlated IFN- $\alpha 2 a$ showed a prolonged circulation time and a mitigated accelerated blood clearance after repeated injections in rats.

\section{Introduction}

Advances in effective protein therapy are hindered by the poor stability, short circulation half-time, and immunogenicity of proteins. ${ }^{1,2}$ The covalent conjugation of poly(ethylene glycol) (PEG) to a protein or PEGylation is clinically proven to favorably alter protein pharmacokinetics by prolonging its circulation time and decreasing its toxicity profile, especially by reducing immunogenicity. ${ }^{3-7}$ Additional advantages of PEGylation include the potential to increase protein solubility and its storage stability. At present, more than 10 PEGylated proteins have been brought to market, and more than 15 are under clinical trials. ${ }^{8}$ Although PEGylation has addressed several limitations and is clinically proven, there are a variety of obstacles and pitfalls to overcome in the continued development of PEGylated protein drugs. In almost all cases, the in vitro biological activity of PEGylated proteins is lower, sometimes significantly lower, than that of the unmodified proteins. ${ }^{4,5}$ This is particularly true for those proteins, which interact with large binding targets whose size is bigger than $900 \mathrm{Da} .{ }^{9}$ For example,

${ }^{a}$ Molecular Engineering and Science Institute, University of Washington, Seattle, WA 98195, USA. E-mail: sjiang@uw.edu

${ }^{b}$ Department of Chemical Engineering, University of Washington, Seattle, WA 98195, USA

† Electronic supplementary information (ESI) available. See DOI: $10.1039 / \mathrm{c} 8 \mathrm{sc} 01777 \mathrm{~h}$
Pegasys, a PEGylated interferon alpha-2a (IFN- $\alpha 2 a$ ) bearing a 40 $\mathrm{kDa}$ branched PEG, is a typical example of a popular protein drug that displays only $7 \%$ in vitro activity of the unmodified IFN- $\alpha 2 a .{ }^{10}$ Even for enzymes dealing with small substrates, a significant bioactivity loss can also be observed. For example, Adagen, for which PEGylation is used to decrease the immunogenicity of the non-human protein, can retain only $18 \%$ bioactivity when compared with the unmodified protein. ${ }^{11}$ PEG is an amphiphilic polymer with both hydrophilic and hydrophobic characters. It was shown previously from both experimental and simulation studies that protein bioactivity decreases after PEGylation due to the hydrophobic nature of PEG. ${ }^{12,13}$ Although various efforts have been made to minimize this effect, such as site-specific PEGylation, ${ }^{14,15}$ the material issue remains unresolved over the last 40 years. ${ }^{16}$

In contrast, zwitterionic polymers, bearing simultaneously a pair of oppositely charged ions in the same moiety while maintaining the overall neutral charge, have been identified recently as a class of extremely hydrophilic materials. ${ }^{17}$ Taking poly(carboxybetaine) (pCB) as an example, its strong electrostatically induced hydration confers an ability to effectively resist nonspecific protein adsorption in complex media. ${ }^{18}$ Due to their nonfouling characteristics, zwitterionic polymers have been used for inhibiting foreign body reactions, ${ }^{19}$ maintaining stem cell phenotypes, ${ }^{20}$ sustaining protein delivery ${ }^{21}$ and stabilizing proteins. ${ }^{22,23}$ In addition, zwitterionic polymer layers 
significantly prolong the in vivo circulation half-life of nanoparticles including liposome, protein and gold particles. ${ }^{24-28}$ Among zwitterionic polymers, $\mathrm{pCB}$ is particularly unique because it is composed of glycine betaine, which is a wellknown protein stabilizer. In a previous study, pCB has been conjugated to chymotrypsin (CT) to test its protein stabilizing effect. ${ }^{12}$ It has been shown that pCB conjugation (or zwitterlation) not only preserves enzyme bioactivity, but also slightly increases its binding affinity to peptide substrates. At the same time, it is found that PEGylation decreases the binding affinity of the enzyme. A study on the fundamental understanding of the difference between PEGylation and zwitterlation was performed before. ${ }^{17}$ For proteins, hydrophobic-hydrophobic interactions are significantly important for enzyme-substrate specific binding (or bioactivity). With PEGylation, the amphiphilicity of PEG reduces the hydrophobic-hydrophobic driving force of enzyme-substrate interactions as confirmed from our molecular simulations. ${ }^{17}$ In contrast, with zwitterlation, its binding affinity is either unaltered or even improved when the binding target of the protein is a small molecule. ${ }^{12}$ Owing to the super-hydrophilicity of pCB polymers, water is drawn away from the hydrophobic regions of the protein, shifting the equilibrium to allow the substrate and binding site to interact. All these results make $\mathrm{pCB}$ a competitive candidate for protein conjugates. Previously, we have demonstrated that zwitterionic pCB conjugates are able to retain the bioactivity of enzymes with relatively small substrates. Here, we performed a systematic study of the effect of zwitterlation on the bioactivity of proteins whose binding target is substantially larger than Keefe studied previously. ${ }^{12}$

\section{Experimental section}

\section{Synthesis of $N$-hydroxysuccinimide poly(carboxybetaine acrylamide) (NHS-pCBAA)}

pCB-NHS was synthesized based on our previous procedure. ${ }^{29}$ Briefly, we firstly synthesized 3-acrylamido- $N$-(2-(tert-butoxy)2-oxoethyl)- $N, N$-dimethylpropane-1-aminium (CBAAM-1-tBu). Then, a typical reversible addition-fragmentation chaintransfer (RAFT) polymerization reaction was performed to yield the $10 \mathrm{kDa}$ and $20 \mathrm{kDa} \mathrm{SH}$-pCB polymer. The final colorless NHS-activated polymer was formed by reaction with AMAS at a 1 : 10 molar ratio in DI water $(\mathrm{pH} 6)$ for $30 \mathrm{~min}$, followed by removal of unreacted AMAS via Amicon spin dialysis tubes and freeze-drying for $48 \mathrm{~h}$.

\section{Synthesis of protein conjugates}

Conjugates of pCB-IFN and PEG-IFN were synthesized by reacting the NHS ester groups of the polymer with available amine groups on the protein. In a typical conjugation reaction, IFN- $\alpha 2 \mathrm{a}$ and NHS-pCB at a $1: 3$ molar ratio were dissolved in $50 \mathrm{mM}$ sodium borate buffer, $\mathrm{pH}$ 9.0. The final protein

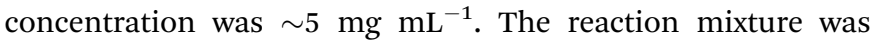
stirred for 2 hours at $4{ }^{\circ} \mathrm{C}$ and stopped by adjusting the $\mathrm{pH}$ of the mixture to 4.5 with glacial acetic acid. The polymer-protein conjugate was isolated via a molecular weight cut-off (MWCO) spin dialysis membrane followed by ion exchange chromatography. The same conjugation and purification methods were used to generate PEGylated IFN- $\alpha 2 \mathrm{a}$. The protein concentrations of the prepared conjugates were determined with the Pierce $^{\mathrm{TM}} 660 \mathrm{~nm}$ protein assay reagent (ThermoFisher Scientific) and confirmed with a Human IFN $\alpha$ (multiple subtypes) bioluminescent ELISA kit (InvivoGen).

\section{In vitro antiproliferative activity}

The procedures of in vitro proliferative activity measurement were employed with lymphoblast cells, Daudi. Daudi cells at passage 4 or 5 were cultured in RPMI 1640 medium containing $10 \%$ (vol/vol) fetal bovine serum (FBS) and antibiotics at $37^{\circ} \mathrm{C}$ in a humidified, $5 \% \mathrm{CO}_{2}$ atmosphere. For bioassays, the cells were suspended in $2 \times 10^{5}$ cells per $\mathrm{mL}$ and seeded in a 96-well plate (Corning) $\left(50 \mu \mathrm{L}, 1 \times 10^{4}\right.$ cells per well). Conjugated protein samples were diluted in culture medium at twice the desired concentrations $(5,10,20,50,100,500$, 1000 , and $10000 \mathrm{pg} \mathrm{mL}^{-1}$ ) and $50 \mu \mathrm{L}$ was added to each test cell. Wells without IFN- $\alpha 2$ a were used as the negative control, defined as $100 \%$ cell viability. After incubation for $72 \mathrm{~h}$, the viability of the cells was determined by the MTT assay.

\section{Pharmacokinetics}

The pharmacokinetics of native and conjugated IFN- $\alpha 2$ a were studied using Sprague Dawley rats (female, body weight 101$125 \mathrm{~g}$ ) as the animal model. All animal experiments adhered to federal guidelines and were approved by the University of Washington Institutional Animal Care and Use Committee (IACUC) under protocol \#4203-01. The rats were randomly distributed to six groups (3 rats per group) and injected with IFN- $\alpha 2 \mathrm{a}, \mathrm{pCB}_{10 \mathrm{~K}}$-IFN, pCB ${ }_{20 \mathrm{~K}}$-IFN, PEG $_{10 \mathrm{~K}}$-IFN, PEG $_{20 \mathrm{~K}}$-IFN, and $\mathrm{PEG}_{40 \mathrm{~K}}$-IFN at a dosage of $100 \mu \mathrm{g}$ IFN-equivalent per $\mathrm{kg}$ body weight via the tail vein. Blood samples were collected from the tail vein at $5 \mathrm{~min}, 4 \mathrm{~h}, 8 \mathrm{~h}, 24 \mathrm{~h}, 28 \mathrm{~h}$ and $72 \mathrm{~h}$ post injection to generate a circulation profile of the different formulations. A pre-dose sample $(0 \mathrm{~h})$ was drawn before the injection of the test proteins as a control sample. The concentration of IFN- $\alpha 2$ a was determined by the ELISA assay according to the instructions of the human IFN $\alpha$ (multiple subtypes) bioluminescent ELISA kit (InvivoGen). Pharmacokinetic parameters were analyzed by PKSolver following the instruction. The IV injections and bleeding procedure were repeated 3 times, with one week between each injection. Five weeks after the first injection, $5 \mathrm{~mL}$ blood was drawn by using cardiac punch, and serum was prepared for antibody detection.

\section{Results and discussion}

IFN- $\alpha 2 \mathrm{a}$ is a small protein $(19.2 \mathrm{kDa})$ which targets large cellular receptors on the cell membrane. In clinical applications, unconjugated IFN- $\alpha 2$ a can be rapidly cleared from the body through renal filtration due to its small size. PEGylation of IFNa2a dramatically increases its circulation time. However, the bioactivity of PEGylated IFN- $\alpha 2 \mathrm{a}$ is only $7 \%$ of its native form. In this work, as illustrated in Fig. 1a and b, zwitterionic polymers 
a

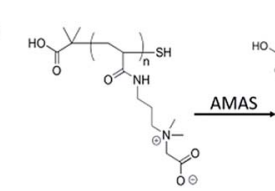

b IFN

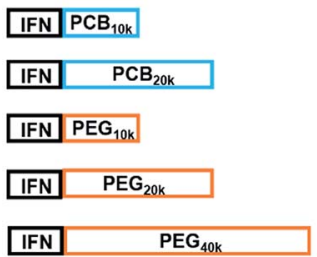

Fig. 1 Synthesis and characterization of zwitterionic polymer-IFN conjugates. (a) Synthetic route to conjugates; (b) schematic illustration of conjugates of different molecular weights; (c) representative sizeexclusion chromatograms for conjugates of different molecular weights.

with different molecular weights were conjugated to IFN- $\alpha 2 \mathrm{a}$ through a two-step method as we reported before, ${ }^{29}$ and the schematic is illustrated in Fig. 1a. To make a fair comparison between zwitterlated and PEGylated conjugates, PEGylated IFN$\alpha 2 \mathrm{a}$ with both similar molecular weights and hydrodynamic sizes to zwitterlated IFN- $\alpha 2$ a were prepared and compared. The size differences of various polymers and IFN- $\alpha 2$ a conjugates are presented in Fig. S1 $\dagger$ and Fig. 1c. After purification, pCB-IFN and PEG-IFN with single-polymer conjugation were obtained. The successful synthesis of mono-PEGylated or monozwitterlated IFN was confirmed by SDS-PAGE analysis (Fig. S2 $\dagger$ ). The hydrodynamic size and polydispersity index of the polymer-IFN conjugates (Table S1 $\dagger$ ) further confirmed the successful preparation and the monodispersity of the conjugates. The conversions and yields of the conjugate reactions are shown in Table S2. $\dagger$

IFNs are highly pleiotropic cytokines and exhibit potent antiproliferative properties. ${ }^{30}$ To demonstrate whether zwitterlation could reduce the bioactivity loss of IFN- $\alpha 2 a$, we employed a widely accepted antiproliferation assay to study the in vitro bioactivity change of zwitterlated and PEGylated IFN- $\alpha 2$ a conjugates. In brief, the antiproliferation assay was performed by serial dilutions in 96-well microtiter plates seeded with Daudi cells, a human lymphoblastoid cell line. After $72 \mathrm{~h}$ incubation, cells were treated with 3-(4,5-dimethylthiazol-2-yl)-2,5-diphenyltetrazolium bromide (MTT) and the microplate reader was analyzed for viability. Antiproliferative activity, expressed as $\mathrm{IC}_{50}$, was calculated by a nonlinear regression method (Fig. 2a). As presented in Fig. 2b, the antiproliferative activity of pCB-IFNs is much higher than that of PEGylated IFNs. Notably, $\mathrm{pCB}_{20 \mathrm{k}}$-IFN and $\mathrm{PEG}_{20 \mathrm{k}}$-IFN have a similar molecular weight, but the antiproliferative activity of $\mathrm{pCB}_{20 \mathrm{k}}$-IFN (62.1\%) is 4.4-fold higher than that of $\mathrm{PEG}_{20 \mathrm{k}}$-IFN (14.2\%). Considering the hydrodynamic volume difference, we also prepared $\mathrm{PEG}_{10 \mathrm{k}}$-IFN, which has a similar hydrodynamic size to $\mathrm{pCB}_{20 \mathrm{k}}$-IFN. The antiproliferative activity of $\mathrm{PEG}_{10 \mathrm{k}}-\mathrm{IFN}$ is $20.9 \%$ and is about $1 / 3$ of $\mathrm{pCB}_{20 \mathrm{k}}$-IFN. These results indicate that $\mathrm{pCB}$ conjugation can better mitigate bioactivity loss than PEGylation.
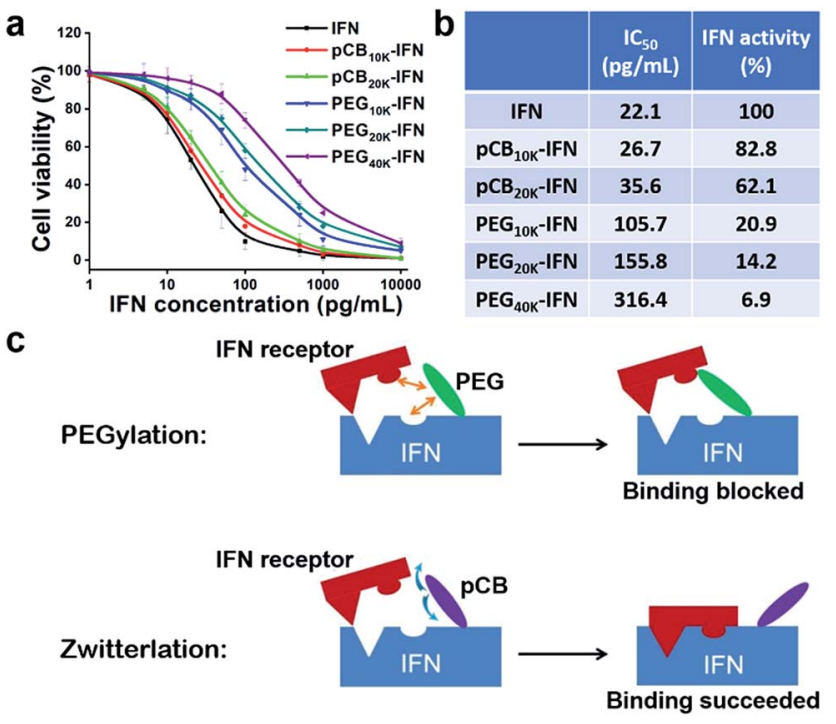

Fig. 2 Zwitterlation retains the most bioactivity of conjugated IFN. (a) Conjugates with serial dilutions were incubated with human Daudi cells for 4 days at $37^{\circ} \mathrm{C}$ in 96 -well tissue culture plates. MTT assay was used for the cell viability assay; (b) antiproliferative activity; (c) schematic illustration of how a zwitterionic conjugate avoids bioactivity loss by effectively eliminating nonspecific interactions.

As presented in Fig. 2c, we hypothesize that the bioactivity loss after PEGylation is mainly attributed to the steric effect and nonspecific interactions of amphiphilic PEG with both the interferon binding domain and interferon receptor. This nonspecific blocking effect sometimes does not significantly affect the bioactivity when the protein size is large, and the substrate size is small (e.g., uricase). However, for conjugated proteins whose receptors have a similar or larger size, this nonspecific blocking usually results in a significant bioactivity loss (e.g., interferon). In contrast to PEGylation, we hypothesize that zwitterionic conjugation could mitigate this bioactivity loss due to the reduced nonspecific interactions of PCB polymers with both the IFN- $\alpha 2$ a binding domain and IFN- $\alpha 2$ a receptor (Fig. 2c). Due to the tightly bound water layer around zwitterionic polymers, nonspecific interactions between either the IFN$\alpha 2$ a or IFN- $\alpha 2$ a receptor and zwitterionic polymers can be minimized. As a result, the bioactivity loss of pCB conjugated IFN- $\alpha 2 a$ can be reduced.

Monomeric PEGylated IFNs suffer from accelerated blood clearance upon repeated injections in monkeys. ${ }^{31}$ In this work, encouraged by the in vitro results, we further examined the in vivo performance of zwitterlated, PEGylated and unconjugated IFN- $\alpha 2$ a conjugates with the same doses injected every week for three weeks. The blood was harvested at different time points to examine the circulation time. As shown in Fig. 3a, for the circulation profile of the first injection, both PEGylation and zwitterlation significantly improve the circulation time when compared with unconjugated IFN- $\alpha 2 \mathrm{a}$. In brief, we observed a 47.8 -fold increase in $t_{1 / 2}$ when $\mathrm{pCB}_{20 \mathrm{k}}$ was conjugated. At the same time, a 26.6-fold increase was observed when PEG with a similar molecular weight $\left(\mathrm{PEG}_{20 \mathrm{k}}\right)$ was conjugated and a 11.9-fold increase was observed when PEG with a similar 

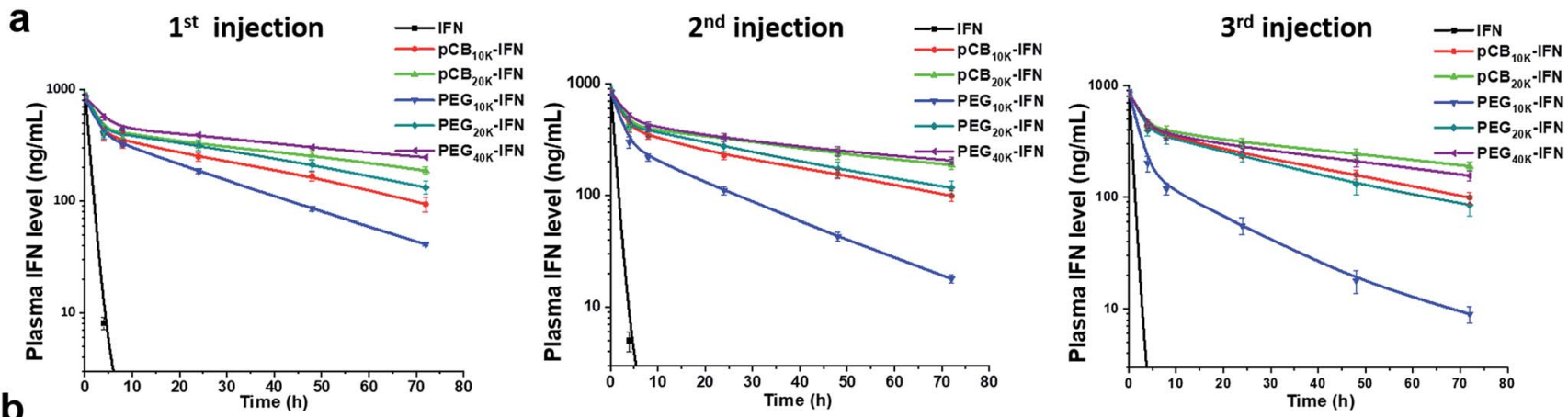

\begin{tabular}{|c|c|c|c|c|c|c|}
\hline \multirow{3}{*}{ Time (h) } & \multirow{2}{*}{\multicolumn{6}{|c|}{$t_{1 / 2}(h)$}} \\
\hline & & & & & & \\
\hline & IFN & $\mathrm{pCB}_{10 \mathrm{~K}^{-I F N}}$ & $\mathrm{PCB}_{20 \mathrm{~K}}-\mathrm{IFN}$ & $\mathrm{PEG}_{10 \mathrm{~K}}$-IFN & $\mathrm{PEG}_{20 \mathrm{~K}^{-}}$IFN & $\mathrm{PEG}_{40 \mathrm{~K}}$-IFN \\
\hline First injection & 1.307 & 26.67 & 62.45 & 15.56 & 34.84 & 69.14 \\
\hline Second injection & 1.104 & 27.56 & 60.57 & 12.45 & 29.23 & 61.35 \\
\hline Third injection & 0.826 & 25.87 & 61.38 & 8.36 & 22.68 & 52.06 \\
\hline
\end{tabular}

Fig. 3 Zwitterlation mitigates the accelerated blood clearance. (a) In vivo circulation profiles of native IFN- $\alpha 2 a$ and $p C B$ or PEG conjugated IFNa2a; (b) pharmacokinetic parameters after repeated injections.

hydrodynamic size $\left(\mathrm{PEG}_{10 \mathrm{k}}\right)$ was conjugated. Notably, the circulation time of $\mathrm{pCB}_{20 \mathrm{k}} \mathrm{-IFN}$ is comparable to that of $\mathrm{PEG}_{40 \mathrm{k}}{ }^{-}$ IFN (Pegasys) while its bioactivity is 9-fold higher although $\mathrm{PCB}_{20 \mathrm{k}}$ is half of $\mathrm{PEG}_{40 \mathrm{~K}}$ in its molecular weight (Fig. 2b). In this work, we found that the increased molecular weight of conjugated polymers could further improve the circulation time. As presented, the $t_{1 / 2}$ of $\mathrm{pCB}_{20 \mathrm{k}}$-IFN shows a 2.3 -fold increase over the $t_{1 / 2}$ of $\mathrm{pCB}_{10 \mathrm{k}}$-IFN. A similar scenario was observed in PEG conjugation where a 2.2-fold increase was achieved when $10 \mathrm{kDa}$ PEG was replaced with $20 \mathrm{kDa}$ PEG.

Upon repeated injection, a significant difference was observed between pCB-IFNs and PEG-IFNs. As presented in Fig. 3a and b, for unconjugated IFN- $\alpha 2 \mathrm{a}$, we noticed a $15.6 \%$ and $36.2 \%$ decrease in $t_{1 / 2}$ after the $2^{\text {nd }}$ and $3^{\text {rd }}$ injections, respectively when compared with the first injection. Despite PEG conjugation can significantly increase the circulation time of IFN- $\alpha 2 \mathrm{a}$ after the $1^{\text {st }}$ injection, the circulation profiles show a $20.0 \%$ and $46.3 \%$ decrease in $t_{1 / 2}$ after the $2^{\text {nd }}$ and $3^{\text {rd }}$ injections respectively for $\mathrm{PEG}_{10 \mathrm{k}}$-IFN, and a $16.2 \%$ and $34.9 \%$ decrease in $t_{1 / 2}$ after the $2^{\text {nd }}$ and $3^{\text {rd }}$ injections respectively for $\mathrm{PEG}_{20 \mathrm{k}}$-IFN. These results show the "accelerated blood clearance" effect ${ }^{32}$ of PEG conjugation after repeated injection. For this reduced circulation time, $\mathrm{PEG}_{10 \mathrm{k}}$-IFN is even more evident than unconjugated IFN- $\alpha 2$ a. In sharp contrast to unconjugated IFN- $\alpha 2 \mathrm{a}$ and PEGylated IFN- $\alpha 2 \mathrm{a}$, zwitterlated IFN- $\alpha 2 \mathrm{a}$ does not show a significant decline in $t_{1 / 2}$ after the $2^{\text {nd }}$ and $3^{\text {rd }}$ injections.

It is known that the surface attachment of hydrophilic polymers like PEG to a protein can significantly prolong the in vivo circulation time by increasing its hydrodynamic size to avoid rapid renal clearance (for small particles) and reducing interactions with both blood components (opsonization) and immune cells in early studies..$^{4,8}$ However, several studies since then have found anti-PEG antibodies after treatment with PEGylated therapies, with titers strongly related to the modification density of PEG chains and the immunogenicity of the anchoring protein..$^{33,34}$ The haptenic character of PEG is considered as the main culprit in the therapeutic efficacy loss of PEGylated products. Recent clinical studies of pegloticase (PEGylated uricase) in refractory chronic gout patients unequivocally demonstrated that the production of anti-PEG antibodies is responsible for the reduction in drug effectiveness-pegloticase loses efficacy in more than $40 \%$ of patients, and the presence of anti-PEG antibodies doubles the risk of infusion reactions. ${ }^{35,36}$ Similar results have also been observed for other PEGylated proteins in clinical use such as PEGasparaginase. ${ }^{37}$ PEGylated nanoparticles such as liposomes also stimulate a strong anti-PEG response, and these antibodies are found to cross-react with different PEGylated products. ${ }^{38,39}$ Furthermore, there is a concern that the prevalence of anti-PEG antibodies was found to be $72 \%(273 / 377)$ in healthy individuals, attributed to daily exposure to consumer products. ${ }^{40}$ However, a cautious examination of whether these pre-existing antibodies have an equivalent effect on different PEGylated proteins is needed. Furthermore, antibodies toward proteins (e.g., peginterferon-alfa ${ }^{41}$ ) can also further reduce the therapeutic effect of PEGylated proteins. Altogether, these findings raise concerns regarding the toxicity and efficacy of PEGylated drugs. As a result, alternatives to this PEGylation strategy are urgently needed. ${ }^{42,43}$ Systematic studies have shown that PEG immunogenicity strongly results from the hydrophobic characteristics of this amphiphilic polymer. ${ }^{44-46}$ Due to the superhydrophilic nature of zwitterionic pCB polymers, we hypothesized that zwitterlation could mitigate the immunogenicity of IFN- $\alpha 2 \mathrm{a}$. At the same time, zwitterionic polymers do not elicit a strong immune response in the body.

To confirm this hypothesis, we further proceeded to analyze the production of IgM and IgG antibodies after repeated injections. The results are summarized in Fig. 4. As presented, both 
a

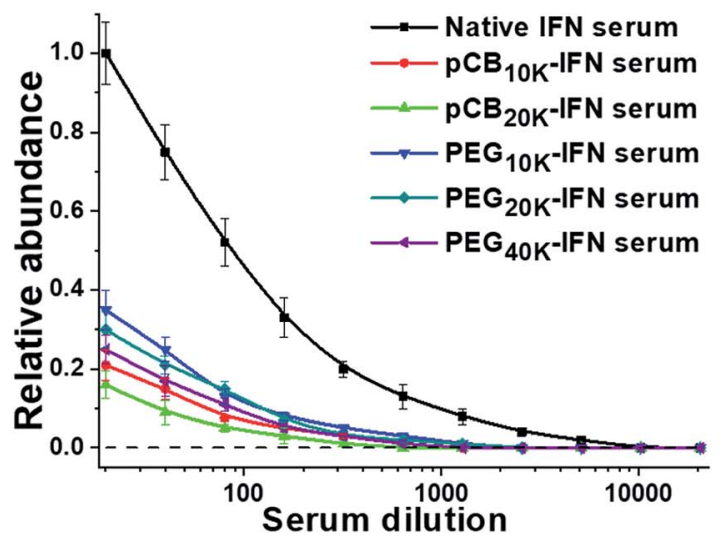

C

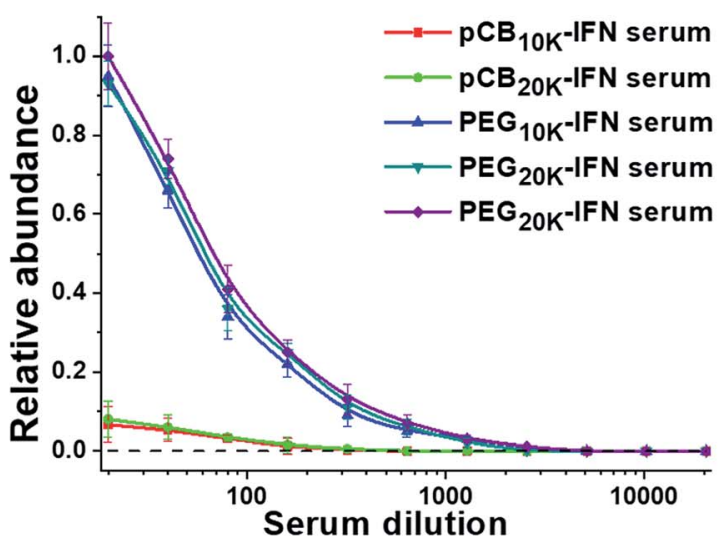

b

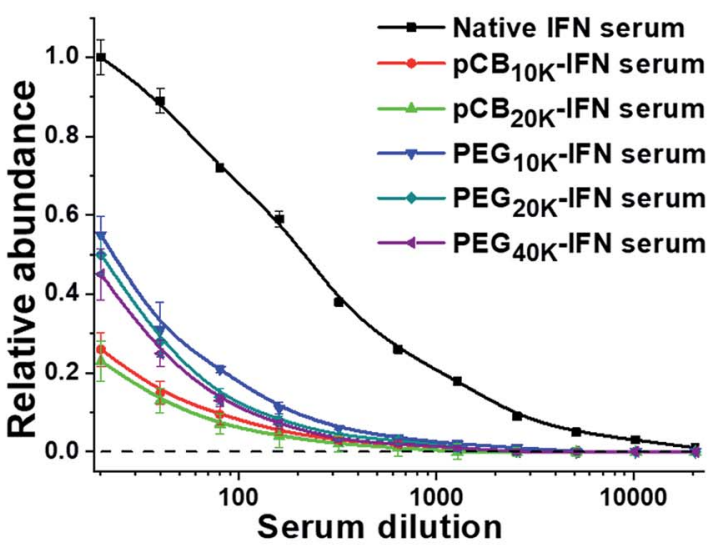

d

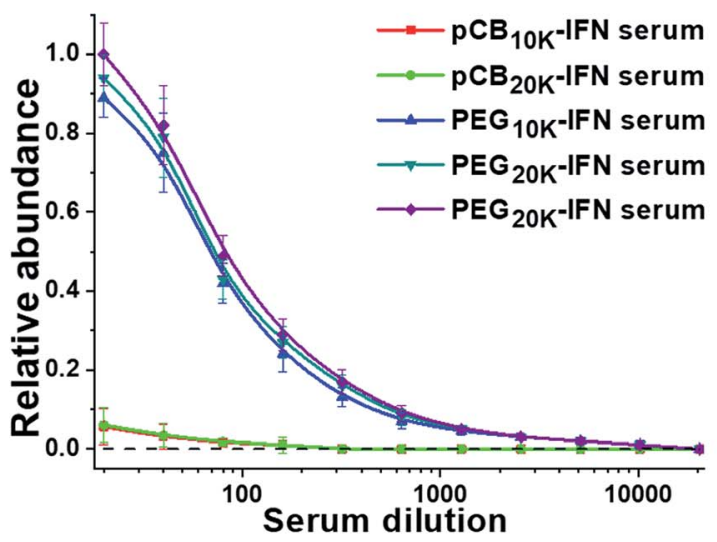

Fig. 4 Zwitterlation mitigates the production of specific antibodies against the polymer and IFN. After 3 injections, IFN-specific IgM (a) and IgG (b) antibodies and polymer-specific $\lg M(c)$ and $\lg G(d)$ antibodies were analysed.

PEGylation and zwitterlation can mitigate the generation of IFN- $\alpha 2 a-s p e c i f i c$ antibodies after repeated injections. For PEGylation, at the lowest dilution, the protein-specific IgM titers for $\mathrm{PEG}_{10 \mathrm{k}}$-IFN and $\mathrm{PEG}_{20 \mathrm{k}}$-IFN groups are $36.7 \%$ and $31.1 \%$ of that of the unconjugated IFN- $\alpha 2$ a group. The proteinspecific IgG titers for $\mathrm{PEG}_{10 \mathrm{k}}$-IFN and $\mathrm{PEG}_{20 \mathrm{k}}$-IFN groups are $57.4 \%$ and $51.1 \%$ of that of the unconjugated IFN- $\alpha 2$ a group. At the same time, it is observed that zwitterlation can further decrease the production of both protein-specific IgM and IgG. At the lowest dilution, the protein-specific IgM titers for $\mathrm{pCB}_{10 \mathrm{k}}{ }^{-}$ IFN and $\mathrm{pCB}_{20 \mathrm{k}}$-IFN groups are $22.4 \%$ and $16.7 \%$ of that of the unconjugated IFN- $\alpha 2$ a group. The protein-specific IgG titers for $\mathrm{pCB}_{10 \mathrm{k}}$-IFN and $\mathrm{pCB}_{20 \mathrm{k}}$-IFN groups are $26.9 \%$ and $23.5 \%$ of that of the unconjugated IFN- $\alpha 2$ a group. These results also indicate that PCB polymers can better protect the conjugated IFN- $\alpha 2 \mathrm{a}$ from immunosurveillance than PEG polymers. We further examined the production of specific IgM and IgG production against PEG and pCB polymers. As presented in Fig. $4 \mathrm{c}$ and d, we observed a dramatic difference between PEG and pCB conjugates for their antibody production specifically against polymers. At the lowest dilution, we found that pCB-IFNs induce negligible anti-polymer production of either IgM or IgG compared with PEG-IFNs. These results indicate that the accelerated blood clearance of PEG-IFN is mainly attributed to the production of antibodies against both IFN- $\alpha 2 \mathrm{a}$ and the PEG polymer. For pCB-IFN, since PCB polymers can mitigate the antibody production against IFN- $\alpha 2$ a and do not elicit specific antibody production against themselves in the body, the accelerated blood clearance can be significantly attenuated.

\section{Conclusions}

In summary, protein-polymer conjugation has been demonstrated to be an effective method to improve the therapeutic result of protein drugs in vivo. However, for proteins whose receptors/substrates have a large size, PEG polymer conjugation often results in a significant loss in protein bioactivity. In this work, we selected IFN- $\alpha 2$ a as a model protein whose in vitro bioactivity can be reduced by more than $90 \%$ after PEGylation. We demonstrate that zwitterionic conjugation can significantly retain the in vitro antiproliferative bioactivity of conjugated IFN$\alpha 2$ a due to the super-hydrophilic nature of zwitterionic polymers, and thus the 'nonspecific blocking' issue in PEGylation can be mitigated. Furthermore, in vivo results show that zwitterionic conjugation prolongs the IFN- $\alpha 2$ a circulation time and attenuates its accelerated blood clearance significantly. Further analysis reveals that zwitterlation mitigates the production of antibodies toward both IFN- $\alpha 2 \mathrm{a}$ and the polymer. This work indicates that 
zwitterionic polymer conjugation may be particularly suitable for the conjugation of therapeutic proteins with large binding targets. Our next step will focus on the in vivo bioactivity study of zwitterlated proteins.

\section{Conflicts of interest}

S. Jiang is a cofounder of Furtim Therapeutics LLC.

\section{Acknowledgements}

This work was funded by the National Science Foundation (DMR-1708436).

\section{Notes and references}

1 B. Leader, Q. J. Baca and D. E. Golan, Nat. Rev. Drug Discovery, 2008, 7, 21-39.

2 S. Frokjaer and D. E. Otzen, Nat. Rev. Drug Discovery, 2005, 4, 298-306.

3 F. M. Veronese and G. Pasut, Drug discovery today, 2005, 10, 1451-1458.

4 F. M. Veronese and A. Mero, BioDrugs, 2008, 22, 315-329.

5 C. S. Fishburn, J. Pharm. Sci., 2008, 97, 4167-4183.

6 J. M. Harris and R. B. Chess, Nat. Rev. Drug Discovery, 2003, 2, 214-221.

7 G. Molineux, Cancer Treat. Rev., 2002, 28, 13-16.

8 P. L. Turecek, M. J. Bossard, F. Schoetens and I. A. Ivens, J. Pharm. Sci., 2016, 105, 460-475.

9 T. J. Dougherty and M. J. Pucci, Antibiotic discovery and development, Springer Science \& Business Media, 2011.

10 B. Podobnik, B. Helk, V. Smilovic, S. Skrajnar, K. Fidler, S. Jevsevar, A. Godwin and P. Williams, Bioconjugate Chem., 2015, 26, 452-459.

11 M. S. Hershfield, R. H. Buckley, M. L. Greenberg, A. L. Melton, R. Schiff, C. Hatem, J. Kurtzberg, M. L. Markert, R. H. Kobayashi and A. L. Kobayashi, N. Engl. J. Med., 1987, 316, 589-596.

12 A. J. Keefe and S. Jiang, Nat. Chem., 2012, 4, 59.

13 C. Leng, H.-C. Hung, S. Sun, D. Wang, Y. Li, S. Jiang and Z. Chen, ACS Appl. Mater. Interfaces, 2015, 7, 16881-16888.

14 S. Shaunak, A. Godwin, J.-W. Choi, S. Balan, E. Pedone, D. Vijayarangam, S. Heidelberger, I. Teo, M. Zloh and S. Brocchini, Nat. Chem. Biol., 2006, 2, 312.

15 B. K. Lee, J. S. Kwon, H. J. Kim, S. Yamamoto and E. Lee, Bioconjugate Chem., 2007, 18, 1728-1734.

16 Y. Qi and A. Chilkoti, Curr. Opin. Chem. Biol., 2015, 28, 181193.

17 Q. Shao and S. Jiang, Adv. Mater., 2015, 27, 15-26.

18 S. Chen, L. Li, C. Zhao and J. Zheng, Polymer, 2010, 51, 52835293.

19 L. Zhang, Z. Cao, T. Bai, L. Carr, J.-R. Ella-Menye, C. Irvin, B. D. Ratner and S. Jiang, Nat. Biotechnol., 2013, 31, 553.

20 T. Bai, F. Sun, L. Zhang, A. Sinclair, S. Liu, J. R. Ella-Menye, Y. Zheng and S. Jiang, Angew. Chem., 2014, 126, 1294312948.

21 G. Sener and M. D. Krebs, RSC Adv., 2016, 6, 29608-29611.
22 R. Rajan and K. Matsumura, Sci. Rep., 2017, 7, 45777.

23 J.-H. Seo, R. Matsuno, Y. Lee, M. Takai and K. Ishihara, Biomaterials, 2009, 30, 4859-4867.

24 S. Bhattacharjee, W. Liu, W. H. Wang, I. Weitzhandler, X. Li, Y. Qi, J. Liu, Y. Pang, D. F. Hunt and A. Chilkoti, ChemBioChem, 2015, 16, 2451-2455.

25 A. Lewis, Y. Tang, S. Brocchini, J.-w. Choi and A. Godwin, Bioconjugate Chem., 2008, 19, 2144-2155.

26 K. P. García, K. Zarschler, L. Barbaro, J. A. Barreto, W. O'Malley, L. Spiccia, H. Stephan and B. Graham, Small, 2014, 10, 2505.

27 P. Zhang, F. Sun, C. Tsao, S. Liu, P. Jain, A. Sinclair, H.-C. Hung, T. Bai, K. Wu and S. Jiang, Proc. Natl. Acad. Sci. U. S. A., 2015, 112, 12046-12051.

28 J. Xie, Y. Lu, W. Wang, H. Zhu, Z. Wang and Z. Cao, Adv. Healthcare Mater., 2017, 6, 1601428.

29 S. Liu and S. Jiang, Nano Today, 2016, 11, 285-291.

30 M. R. Walter, R. Bordens, T. L. Nagabhushan, B. R. Williams, R. B. Herberman, C. A. Dinarello, E. C. Borden, P. P. Trotta, S. Pestka and L. M. Pfeffer, Cancer Biother.Radiopharm., 1998, 13, 143-154.

31 X. Hu, K. Olivier, E. Polack, M. Crossman, K. Zokowski, R. S. Gronke, S. Parker, Z. Li, I. Nestorov and D. P. Baker, J. Pharmacol. Exp. Ther., 2011, 338, 984-996.

32 Q. Yang and S. K. Lai, Wiley Interdiscip. Rev.: Nanomed. Nanobiotechnol., 2015, 7, 655-677.

33 R. P. Garay, R. El-Gewely, J. K. Armstrong, G. Garratty and P. Richette, Expert Opin. Drug Delivery, 2012, 9, 1319-1323.

34 A. Richter and E. Åkerblom, Int. Arch. Allergy Appl. Immunol., 1983, 70, 124-131.

35 M. S. Hershfield, N. J. Ganson, S. J. Kelly, E. L. Scarlett, D. A. Jaggers and J. S. Sundy, Arthritis Res. Ther., 2014, 16, R63.

36 P. E. Lipsky, L. H. Calabrese, A. Kavanaugh, J. S. Sundy, D. Wright, M. Wolfson and M. A. Becker, Arthritis Res. Ther., 2014, 16, R60.

37 J. K. Armstrong, G. Hempel, S. Koling, L. S. Chan, T. Fisher, H. J. Meiselman and G. Garratty, Cancer, 2007, 110, 103-111. 38 T. Ishida and H. Kiwada, Int. J. Pharm., 2008, 354, 56-62.

39 K. Shiraishi, M. Hamano, H. Ma, K. Kawano, Y. Maitani, T. Aoshi, K. J. Ishii and M. Yokoyama, J. Controlled Release, 2013, 165, 183-190.

40 Q. Yang, T. M. Jacobs, J. D. McCallen, D. T. Moore, J. T. Huckaby, J. N. Edelstein and S. K. Lai, Anal. Chem., 2016, 88, 11804-11812.

41 A. A. van der Eijk, J. M. Vrolijk and B. L. Haagmans, N. Engl. J. Med., 2006, 354, 1323-1324.

42 E. M. Pelegri-O'Day, E.-W. Lin and H. D. Maynard, J. Am. Chem. Soc., 2014, 136, 14323-14332.

43 T. J. Styslinger, N. Zhang, V. S. Bhatt, N. Pettit, A. F. Palmer and P. G. Wang, J. Am. Chem. Soc., 2012, 134, 7507-7515.

44 M. G. Saifer, L. D. Williams, M. A. Sobczyk, S. J. Michaels and M. R. Sherman, Mol. Immunol., 2014, 57, 236-246.

45 E. Schneck, I. Berts, A. Halperin, J. Daillant and G. Fragneto, Biomaterials, 2015, 46, 95-104.

46 M. R. Sherman, L. D. Williams, M. A. Sobczyk, S. J. Michaels and M. G. Saifer, Bioconjugate Chem., 2012, 23, 485-499. 